\title{
Coronary sinus Reducer: An adjunctive tool for the treatment of patients with chronic total occlusion of the right coronary artery
}

\author{
Maayan Konigstein \\ Division of Cardiology, The Tel-Aviv Sourasky Medical Center and the Sackler School of Medicine, Tel Aviv University, Tel Aviv, Israel
}

\section{Related article}

by Mrak et al.

\author{
Correspondence to: \\ Maayan Konigstein, MD, PhD, \\ Division of Cardiology, \\ The Tel-Aviv Sourasky Medical \\ Center and the Sackler School \\ of Medicine, \\ Tel Aviv University, \\ P.O.B 39040, Ramat Aviv, \\ Tel Aviv 69978, Israel, \\ phone: +972364 081 11, \\ e-mail: \\ maayan.konigstein@gmail.com \\ Copyright by the Author(s), 2022 \\ DOI: 10.33963/KP.a2022.0001 \\ Received: \\ December 12, 2021 \\ Accepted: \\ December 12, 2021 \\ Early publication date: \\ January 4, 2022
}

Angina is the most common symptom of myocardial ischemia, affecting more than 100 million people worldwide. Contemporary treatment of angina is focused on improving coronary arterial blood flow by medical treatment and revascularization [1]. Effective treatment for chronic angina, when symptoms are refractory to medical and interventional therapies, is a major unmet need. The group of "no-option" refractory angina patients includes patients with severe obstructive coronary artery disease (CAD) unsuitable for revascularization, patients who continue to suffer from angina following successful revascularization, and patients with angina and non-obstructive CAD (ANOCA) [2, 3].

When treating these patients, it is of great importance to practice a patient-centered health assessment approach, measuring the success of therapy by its effect on patients' symptoms, functional status, and quality of life, rather than hard clinical endpoints such as myocardial infarction or death.

In this context, the coronary sinus (CS) Reducer is a novel technology designed to improve quality of life and functional capacity by reducing angina burden. The clinical utilization of this device-based therapy for refractory angina continues to grow, with encouraging clinical evidence to support its safety and efficacy [4-7]. The Reducer is the only therapy that attempts to improve angina by acting on the postcapillary myocardial circulation.

One important sub-group of patients with chronic angina is that including pa- tients with chronic total occlusion (CTO). The implantation of CS Reducer has emerged as an attractive alternative therapy to reduce ischemia and improve symptoms of angina in CTO patients in whom other therapies failed and angina persists.

Zivelonghi et al. [8] were the first to report the clinical benefit of the Reducer in non-revascularized CTO patients suffering from angina. They also reported that in contrast to earlier beliefs, patients with CTO of the right coronary artery (RCA) experience clinical improvement following Reducer implantation.

It had been previously assumed that the Reducer would not be effective in patients with ischemia derived from the RCA because the two veins draining the RCA territory drain into the CS near its ostium. The Reducer is usually implanted about $2 \mathrm{~cm}$ distal to the ostium, and therefore, the elevated backward pressure induced by the CS narrowing is not supposed to affect the veins draining the RCA territory. For this reason, the design of COSIRA and COSIRA II randomized sham-control trials excluded patients with angina derived solely from RCA disease.

In the current issue of Kardiologia Polska (Kardiol Pol, Polish Heart Journal), Mrak et al. [9] investigated the impact of Reducer implantation in patients with CTO of the RCA. Their work shows that alleviation of angina and improvement of quality of life (QoL) were comparable in patients with CTO of the RCA and those with ischemia derived from the left coronary arteries. This study suggests that 
the paradigm according to which the Reducer alleviates ischemia only in the territories drained by veins, where it causes backward pressure elevation, may have been incorrect. The explanation suggested by the authors is that the Reducer induces an increase of backward pressure in the non-ischemic region, which augments coronary collateral flow, and thus improves perfusion of the ischemic region exposed to lower tissue perfusion pressure. It has been recently shown that CS pressure elevation by the PICSO system improves microvascular blood flow and absolute coronary blood flow [10]. Likewise, the narrowing caused by the Reducer within the CS increases backward pressure in the coronary venous system. The increased backward pressure causes a slight diameter dilatation of the venules, capillaries, and arterioles, which translates into a reduction in resistance to flow, and increased microvascular coronary blood flow. The overall improvement in microvascular blood flow affects all territories of the myocardium, including the myocardium supplied by the RCA. The potential positive effect of the Reducer on microvascular function should be further evaluated and is currently investigated in several medical centers.

\section{Article information}

Conflict of interest: None declared.

Open access: This article is available in open access under Creative Common Attribution-Non-Commercial-No Derivatives 4.0 International (CC BY-NC-ND 4.0) license, allowing to download articles and share them with others as long as they credit the authors and the publisher, but without permission to change them in any way or use them commercially. For commercial use, please contact the journal office at kardiologiapolska@ptkardio.pl.

\section{REFERENCES}

1. GBD 2015 Mortality and Causes of Death Collaborators. Global, regional, and national life expectancy, all-cause mortality, and cause-specific mortality for 249 causes of death, 1980-2015: a systematic analysis for the Global Burden of Disease Study 2015. Lancet. 2016; 388(10053): 1459-1544, doi: 10.1016/S0140-6736(16)31012-1, indexed in Pubmed: 27733281.

2. Crea F, Merz CB, Beltrame J, et al. Mechanisms and diagnostic evaluation of persistent or recurrent angina following percutaneous coronary revascularization. Eur Heart J. 2019; 40(29): 2455-2462, doi: 10.1093/eurheartj/ehy857, indexed in Pubmed: 30608528.

3. Abdallah MS, Wang K, Magnuson EA, et al. Quality of Life After Surgery or DES in Patients With 3-Vessel or Left Main Disease. J Am Coll Cardiol. 2017; 69(16): 2039-2050, doi: 10.1016/j.jacc.2017.02.031, indexed in Pubmed: 28427580

4. Konigstein M, Giannini F, Banai S. The Reducer device in patients with angina pectoris: mechanisms, indications, and perspectives. Eur Heart J. 2017; 39(11): 925-933, doi: 10.1093/eurheartj/ehx486, indexed in Pubmed: 29020417.

5. Verheye S, Agostoni P, Giannini F, et al. Coronary sinus narrowing for the treatment of refractory angina: a multicentre prospective open-label clinical study (the REDUCER-I study). Eurolntervention. 2021; 17(7): 561-568, doi: 10.4244/eij-d-20-00873, indexed in Pubmed: 33319762.

6. Ponticelli F, Khokhar A, Leenders G, et al. Safety and efficacy of coronary sinus narrowing in chronic refractory angina: Insights from the RESOURCE study. Int J Cardiol. 2021; 337: 29-37, doi: 10.1016/j.jjcard.2021.05.034, indexed in Pubmed: 34029618.

7. Verheye $\mathrm{S}$, Jolicœur $\mathrm{E}$, Behan $\mathrm{M}$, et al. Efficacy of a device to narrow the coronary sinus in refractory angina. N Engl J Med. 2015; 372(6): 519-527, doi: 10.1056/nejmoa1402556, indexed in Pubmed: 25651246.

8. Zivelonghi C, Verheye S, Timmers L, et al. Efficacy of coronary sinus reducer in patients with non-revascularized chronic total occlusions. Am J Cardiol. 2020; 126: 1-7, doi: 10.1016/j.amjcard.2020.03.042, indexed in Pubmed: 32345474.

9. Mrak M, Pavšič N, Ponticelli F, et al. Efficacy of coronary sinus reducer implantation in patients with chronic total occlusion of the right coronary artery. Kardiol Pol. 2022; 80(1): 25-32, doi: 10.33963/KP.a2021.0132, indexed in Pubmed: 34643262.

10. De Maria GL, Alkhalil M, Borlotti A, et al. Index of microcirculatory resistance-guided therapy with pressure-controlled intermittent coronary sinus occlusion improves coronary microvascular function and reduces infarct size in patients with ST-elevation myocardial infarction: the Oxford Acute Myocardial Infarction - Pressure-controlled Intermittent Coronary Sinus Occlusion study (OxAMI-PICSO study). Eurolntervention. 2018; 14(3): e352-e359, doi: 10.4244/eij-d-18-00378, indexed in Pubmed: 29792403. 